\title{
Bidirectional Isolated DC-DC Converter with High Static Gain: Analysis and Experimentation
}

\author{
Ygor Pereira Marca and Ivo Barbi, Life Fellow, IEEE
}

\begin{abstract}
A bidirectional isolated DC-DC converter with high efficiency and static gain, formed by the combination of a FBZVS-PWM and a current fed push-pull converter is presented in this paper. These features are accomplished through a partial regeneration of the energy stored in the transformer's leakage inductance with an active clamping voltage circuit performed by a buck converter. Normally, current-fed push-pull converters have an energy loss in passive snubber circuits. The converter description, operation principles, waveforms, modeling, design and the experimental results of a 2000 Watts prototype are presented. The proposed converter can be implemented in high power applications that require bidirectional power flow and galvanic isolation, such as DC microgrids and electric vehicle battery chargers.
\end{abstract}

Index Terms - Battery charger, bidirectional DC-DC converter, buck converter, current-fed push-pull, full-bridge ZVS-PWM, isolated bidirectional.

\section{INTRODUCTION}

Due to the climate changes that have been occurring in recent decades, several organizations have started to look for technologies that employ renewable energy sources because of their lower environmental impact compared to fossil fuels. Most of these sources are seasonal by its nature, which require an energy storage system to supply the load in periods when there is no power being generated [1].

To charge and discharge a battery energy storage system (BESS), a bidirectional DC-DC converter is more appropriate since it has less components than two individual unidirectional DC-DC converters for each power flow direction. In addition, the galvanic isolation provided by a medium frequency transformer increases safety.

There are many topologies of isolated bidirectional DCDC converters. However, most of them present some disadvantages as poor efficiency, high ripple current at the low voltage side and high breakdown voltage of the switches that must be suppressed using snubber circuits. Nowadays, the main topology for high power applications is the dual active bridge (DAB) converter as presented in [2], but there are other alternatives that employ the full-bridge [3], halfbridge [4], push-pull [5], and resonant converters [6]-[7].

While DAB has been deeply studied, other topologies are still a challenge. For instance, the assimilation of the fullbridge and current-fed push-pull converters cause an energy stored in the transformer's leakage inductance $\left(\mathrm{L}_{\mathrm{lk}}\right)$ that adds to the reverse recovery current of push-pull switches' antiparallel diodes. This energy is discharged on the switches' intrinsic capacitors, demanding voltage regulator circuits that decrease the converter's efficiency [8]-[9].

In this paper, we present an efficient isolated bidirectional DC-DC converter for high power applications with high static gain, low breakdown voltage across the switches and low current ripple at the low voltage side.

\section{CONVERTER ANALYSIS}

\section{A. Power Stage Description}

The converter designed by the authors in [10] is based on an integration of a DC-DC full-bridge ZVS-PWM [11] in the primary side of the medium frequency transformer and a current-fed push-pull in the secondary side, as shown in Fig. 1. This integration requires voltage clamping circuits on switches $\mathrm{S}_{5}$ and $\mathrm{S}_{6}$ to limit their breakdown voltages.

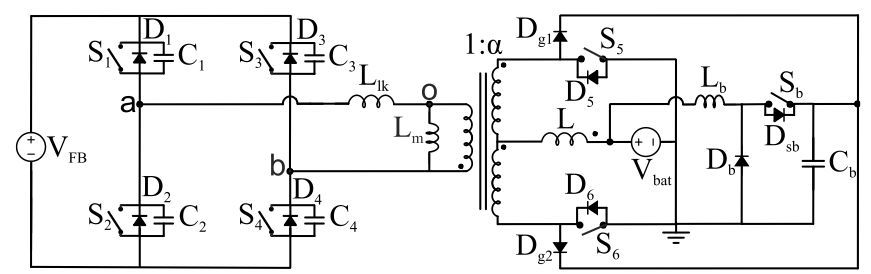

Fig. 1. Isolated bidirectional DC-DC converter proposed.

The transformer with turns ratio equals to $\alpha$ has a small leakage inductance, so it does not accumulate much energy, which reduce the losses in the clamping circuit. However, this inductance provides energy to charge and discharge the commutation capacitors that is necessary to achieve soft switching, which increases the converter's performance.

There are many clamping circuits to recycle the energy from the transformer leakage inductance [12]. This paper proposes a buck converter to transfer the energy accumulated in the leakage inductance back to the low voltage side instead of losing this energy to passive circuits, increasing efficiency and imposing a desirable low voltage across the switches.

\section{B. Operation Principles}

The gate signals of each switch are presented in Fig. 2, which the signals of each leg are complementary. Additionally, the voltage across the transformer's primary side $\left(\mathrm{V}_{\mathrm{ab}}\right)$ and power transferred to the battery are controlled by the shift angle between the converter's legs $(\phi)$, which $0^{\circ}$ represents the maximum power transfer and $180^{\circ}$ represents zero power transfer.

The modulation is performed in order to switch $\mathrm{S}_{5}$ gates off at the time voltage $V_{a b}$ is negative and switch $S_{6}$ turns off when voltage $\mathrm{V}_{\mathrm{ab}}$ is positive. Then, there will be no shortcircuit and voltage induced in the secondary side at the same time. 


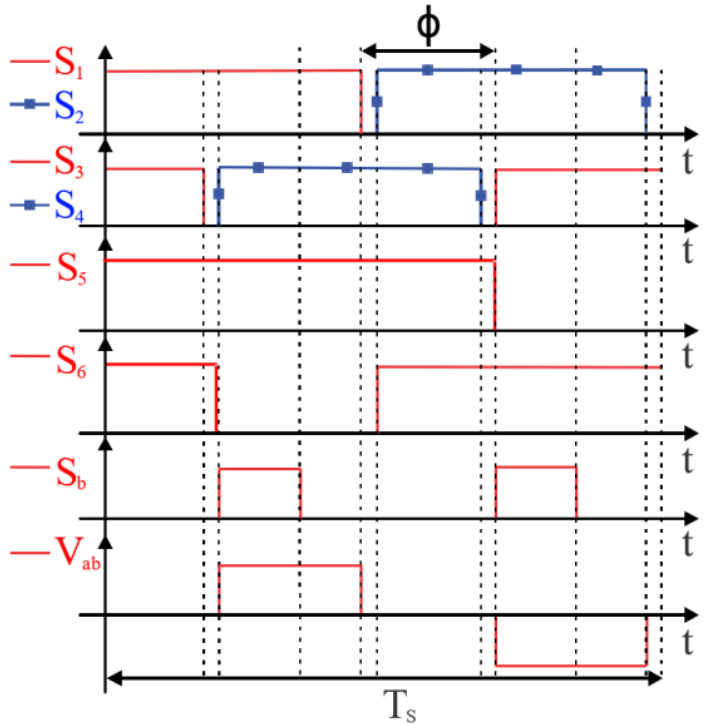

Fig. 2. Gate signals of the converter's switches.

Although buck's gate signal is synchronized with the bidirectional converter and has two times its frequency as presented in Fig. 2, the converter operates regardless this synchronism.

The bidirectional converter has two power flow directions that will be named positive and negative. The positive direction refers to power transferred from high voltage source $\left(\mathrm{V}_{\mathrm{FB}}\right)$ to low voltage source $\left(\mathrm{V}_{\text {bat }}\right)$ and negative indicates the opposite power flow. Since topological states are symmetric for half commutation period, only seven time intervals will be necessary to understand the converter's operation for each power flow direction.

The topological states of the positive power flow are given in Fig. 3, and each time interval is described as follows: a) Time interval [ $\left.\mathbf{t}_{0}-\mathbf{t}_{1}\right]$ : At time $t_{0}$, the switches $S_{1}$, $\mathrm{S}_{3}, \mathrm{~S}_{5}$ and $\mathrm{S}_{6}$ are turned on, so voltage $\mathrm{V}_{\mathrm{ab}}$ is zero. However, the current in the leakage inductor $\left(\mathrm{I}_{\mathrm{Llk}}\right)$ tends to flow through diode $\mathrm{D}_{1}$ because it has a lower resistance than the MOSFET $\mathrm{S}_{1}$. In addition, current in the secondary side $\left(\mathrm{I}_{\mathrm{L}}\right)$ flows through switch $\mathrm{S}_{6}$ and current stored in the inductor $\mathrm{L}_{b}$ is discharged in $\mathrm{V}_{\text {bat }}$.

b) Time interval $\left[\mathbf{t}_{1}-\mathbf{t}_{2}\right]$ : This time interval represents the period which soft switching occurs. Therefore, when $S_{3}$ is gated off and $\mathrm{S}_{4}$ has not been switched on yet, primary side current charges capacitor $\mathrm{C}_{3}$ and discharges $\mathrm{C}_{4}$. In addition, the secondary side is short-circuited and voltage $\mathrm{V}_{\mathrm{ob}}$ is zero.

c) Time interval $\left[\mathbf{t}_{2}-\mathbf{t}_{3}\right]$ : At the instant $t_{2}$, switch $S_{4}$ is gated on. The current $\mathrm{I}_{\mathrm{Llk}}$ has a negative value that gradually increases, then it flows through diodes $\mathrm{D}_{1}$ and $\mathrm{D}_{4}$ until reaches zero. Additionally, the anti-parallel diode $\mathrm{D}_{6}$ of switch $\mathrm{S}_{6}$ has a reverse recovery current that flows through diode $\mathrm{D}_{\mathrm{g} 2}$ because it is forward biased, charging buck's capacitor $\left(\mathrm{C}_{\mathrm{b}}\right)$ and inductor $\left(\mathrm{L}_{\mathrm{b}}\right)$.

d) Time interval $\left[\mathbf{t}_{\mathbf{3}}-\mathbf{t}_{\mathbf{4}}\right]$ : This interval begins when the current in $\mathrm{L}_{\mathrm{k}}$ is zero and starts to rise linearly. In this step, voltage $\mathrm{V}_{\mathrm{ob}}$ is still zero, which represents a loss of duty cycle. In addition, current flows through switches $S_{1}$ and $S_{4}$ because current $\mathrm{I}_{\mathrm{Llk}}$ has changed its direction.

e) Time interval $\left[\mathbf{t}_{4}-\mathbf{t}_{5}\right]$ : At time $t_{4}$, current $I_{L l k}$ reaches its nominal value. Since voltage $V_{o b}$ is not zero anymore, the power is transferred from $V_{F B}$ to $V_{\text {bat }}$ through switch $\mathrm{S}_{5}$. As the energy from the reverse recovery ends and switch $S_{b}$ is still turned on, the energy stored in the capacitor $\mathrm{C}_{\mathrm{b}}$ discharges into the secondary voltage source through the inductor $\mathrm{L}_{\mathrm{b}}$.

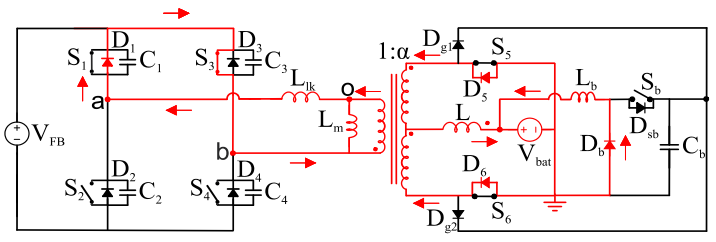

(a)

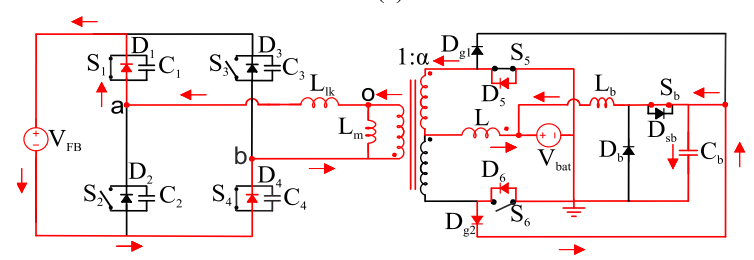

(c)

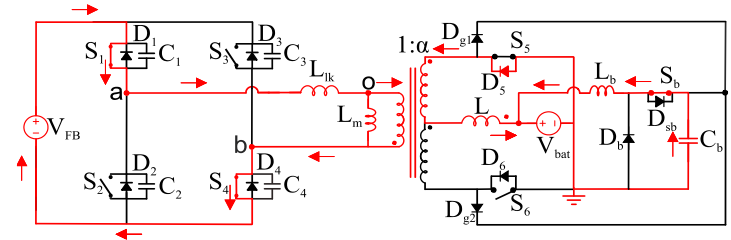

(e)

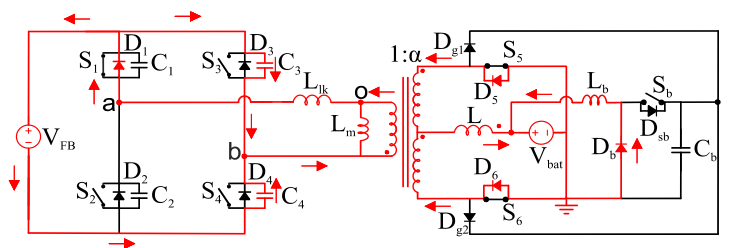

(b)

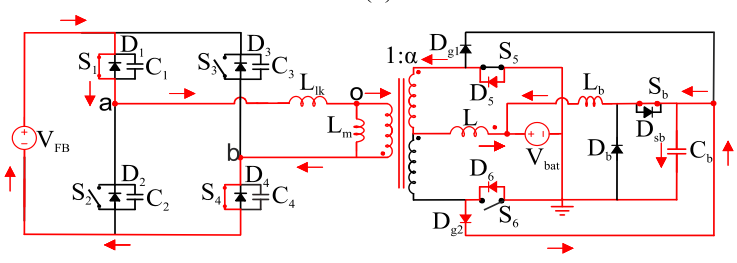

(d)

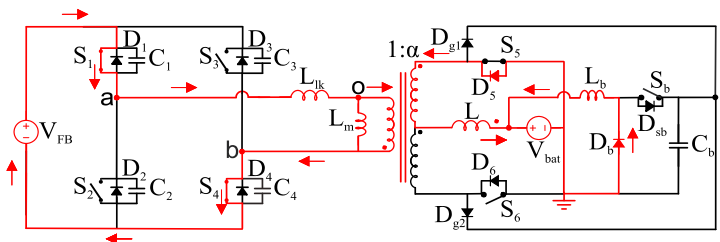

(f)

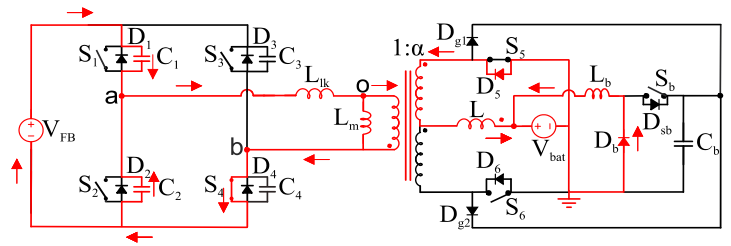

(g)

Fig. 3. Topological states of the time intervals: (a) time interval $\left[t_{0}-t_{1}\right]$, (b) time interval $\left[t_{1}-t_{2}\right]$, (c) time interval $\left[t_{2}-t_{3}\right]$, (d) time interval $\left[t_{3}-t_{4}\right]$, (e) time interval $\left[\mathrm{t}_{4}-\mathrm{t}_{5}\right]$, (f) time interval $\left[\mathrm{t}_{5}-\mathrm{t}_{6}\right]$ and $(\mathrm{g})$ time interval $\left[\mathrm{t}_{6}-\mathrm{t}_{7}\right]$ for the positive power flow direction. 
f) Time interval $\left[\mathbf{t}_{\mathbf{5}}-\mathbf{t}_{\mathbf{6}}\right]$ : At time $\mathrm{t}_{5}$, switch $\mathrm{S}_{\mathrm{b}}$ is gated off. Therefore, only the inductor $\mathrm{L}_{\mathrm{b}}$ provides energy to the battery.

g) Time interval $\left[\mathbf{t}_{\mathbf{6}}-\mathbf{t}_{7}\right]$ : At time $\mathrm{t}_{6}$, there is a deadtime between switches $S_{1}$ and $S_{2}$. Then, when $S_{1}$ turns off and $\mathrm{S}_{2}$ has not been turned on yet, the current stored in $\mathrm{L}_{\mathrm{lk}}$ charges $\mathrm{C}_{1}$ and discharges $\mathrm{C}_{2}$. Moreover, since switch $\mathrm{S}_{\mathrm{b}}$ is turned off, $\mathrm{L}_{\mathrm{b}}$ provides energy to the $\mathrm{V}_{\text {bat }}$.

The main waveforms of the converter operating with positive power flow direction are represented in Fig. 4, which time intervals $t_{0}$ to $t_{7}$ describe the topological states presented in Fig. 3.

In addition, the topological states of the negative power flow are given in Fig. 5, and each time interval is described as follows:

a) Time interval [ $\left.\mathbf{t}_{\mathbf{0}}-\mathbf{t}_{1}\right]$ : At time $t_{0}$, switches $S_{5}$ and $\mathrm{S}_{6}$ are gated on. Thus, there is zero voltage across $\mathrm{V}_{\mathrm{ab}}$. Since the switches $S_{1}$ and $S_{3}$ are turned on, the current $I_{L l k}$ flows through them and at the secondary side current $I_{L}$ starts to change its trajectory from switch $S_{6}$ to $S_{5}$ in a linear way because they are short-circuited.

b) Time interval [ $\left.\mathbf{t}_{1}-\mathbf{t}_{2}\right]$ : On this time interval switch $\mathrm{S}_{3}$ is gated off while $\mathrm{S}_{4}$ has not been gated on yet. Nonetheless, there is an intrinsic diode $\mathrm{D}_{3}$ in anti-parallel with $\mathrm{S}_{3}$ that conducts the current. Therefore, since current does not flow through the capacitors $\mathrm{C}_{3}$ and $\mathrm{C}_{4}$ like in the positive operation, soft commutation is not achieved.

c) Time interval $\left[\mathbf{t}_{2}-\mathbf{t}_{3}\right]$ : At the instant $t_{2}$, switch $S_{4}$ is turned on and $\mathrm{S}_{6}$ is turned off. Thus, there is a positive voltage across $\mathrm{V}_{\mathrm{ab}}$ and current $\mathrm{I}_{\mathrm{Llk}}$ flows through $\mathrm{S}_{1}$ and $\mathrm{S}_{4}$. Additionally, when $\mathrm{D}_{6}$ is gated off the leakage inductance energy is transferred to $C_{b}$ and $V_{b a t}$ since the diode $D_{g 2}$ is forward biased.

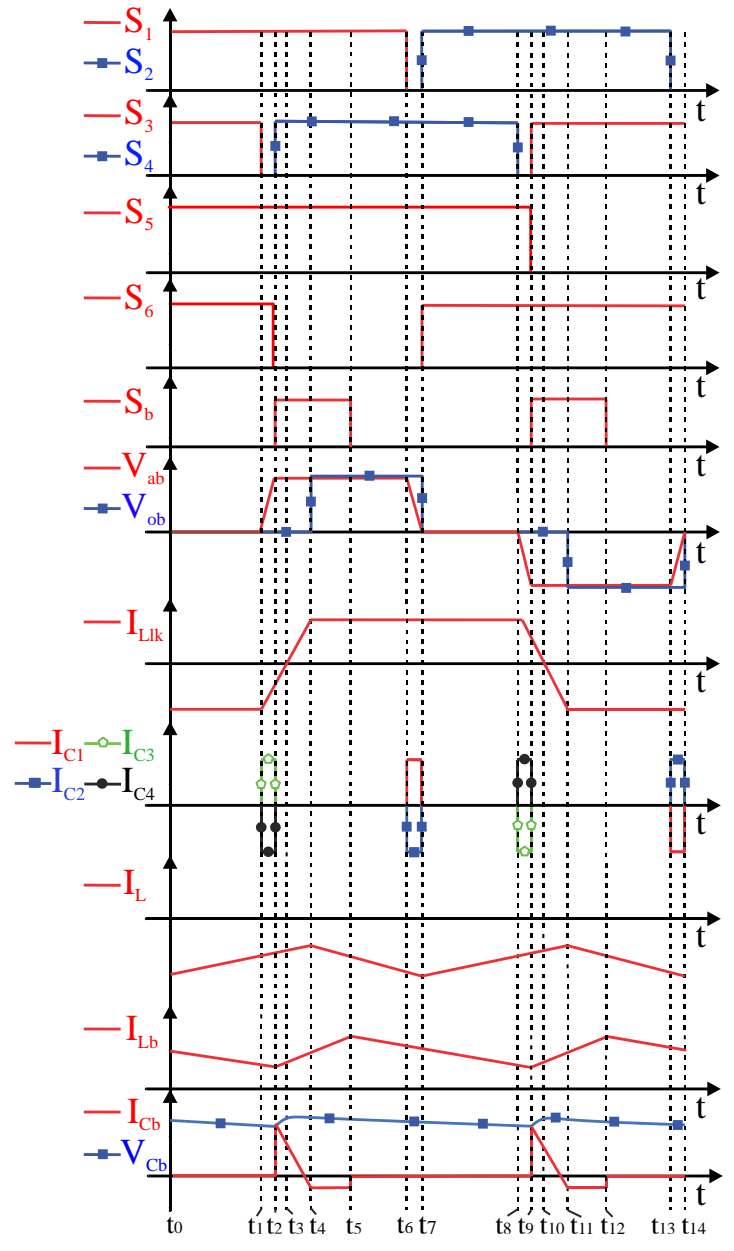

Fig. 4. Main waveforms of converter operating with positive power flow direction with time intervals $\mathrm{t}_{0}$ to $\mathrm{t}_{7}$ described.

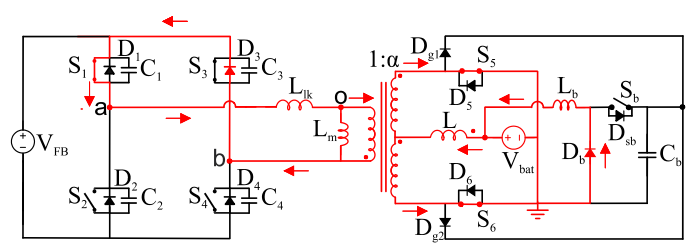

(a)

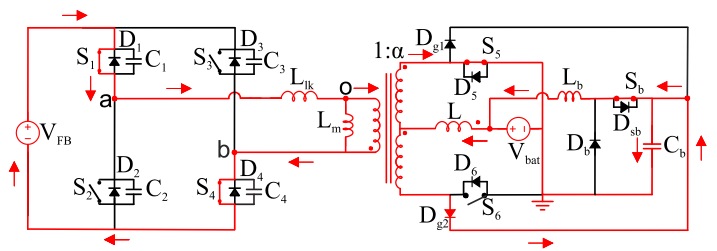

(c)

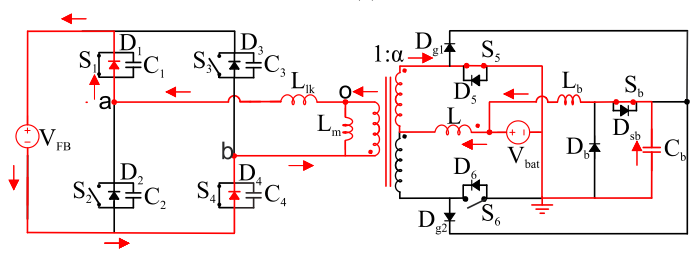

(e)

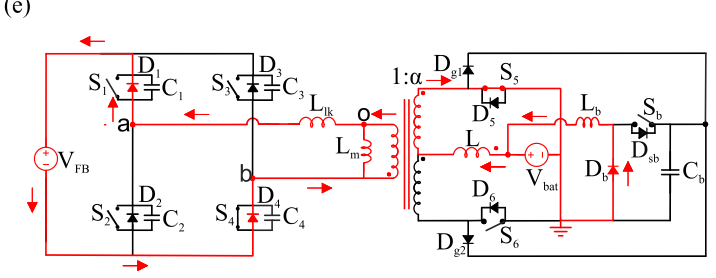

(g)

Fig. 5. Topological states of the time intervals: (a) time interval $\left[t_{0}-t_{1}\right],(b)$ time interval $\left[t_{1}-t_{2}\right],(c)$ time interval $\left[t_{2}-t_{3}\right],(d)$ time interval $\left[t_{3}-t_{4}\right],(e)$ time interval $\left[t_{4}-t_{5}\right]$, (f) time interval $\left[t_{5}-t_{6}\right]$ and $(g)$ time interval $\left[t_{6}-t_{7}\right]$ for the negative power flow direction. 
d) Time interval $\left[\mathbf{t}_{3}-\mathbf{t}_{4}\right]$ : On this time interval, the voltage clamping circuit is still transferring energy to $V_{\text {bat }}$ and switch $\mathrm{S}_{5}$ is responsible to transfer power from $V_{\mathrm{FB}}$ to $\mathrm{V}_{\text {bat }}$. Since $\mathrm{I}_{\mathrm{Llk}}$ changes its direction, the diodes $\mathrm{D}_{1}$ and $\mathrm{D}_{4}$ conduct the current.

e) Time interval $\left[\mathbf{t}_{\mathbf{4}}-\mathbf{t}_{5}\right]$ : At time $t_{4}$, the current $\mathrm{I}_{\mathrm{Llk}}$ has been completely discharged, the $\mathrm{C}_{\mathrm{b}}$ discharges into $\mathrm{V}_{\text {bat }}$ to keep a steady clamping voltage on switches $S_{5}$ and $S_{6}$.

f) Time interval $\left[\mathbf{t}_{5}-\mathbf{t}_{6}\right]$ : At time $t_{5}$, the switch $S_{b}$ is gated off. Therefore, the capacitor $\mathrm{C}_{\mathrm{b}}$ does not provide energy to $\mathrm{V}_{\text {bat }}$ anymore, only $\mathrm{L}_{\mathrm{b}}$.

g) Time interval $\left[\mathbf{t}_{6}-\mathbf{t}_{7}\right]$ : At time $t_{6}$, switch $S_{1}$ turns off while $S_{2}$ has not been turned on yet. Since there are intrinsic anti-parallel diodes, $\mathrm{I}_{\mathrm{Llk}}$ continues to flow through $\mathrm{D}_{1}$ and $\mathrm{D}_{4}$. However, in this interval, $\mathrm{V}_{\mathrm{ob}}$ is zero.

In summary, Fig. 6 presents the main waveforms for the negative power flow. The voltage stresses are equal to the voltage $V_{F B}$ on the switches $S_{1}, S_{2}, S_{3}$ and $S_{4}$, and to $V_{C b}$ on the switches $\mathrm{S}_{5}, \mathrm{~S}_{6}$ and $\mathrm{S}_{\mathrm{b}}$. In addition, the current stresses are calculated with the leakage inductance current $\left(\mathrm{I}_{\mathrm{Llk}}\right)$ waveform for the switches $S_{1}, S_{2}, S_{3}$ and $S_{4}$ and with the inductor current $\left(I_{L}\right)$ for $S_{5}$ and $S_{6}$.

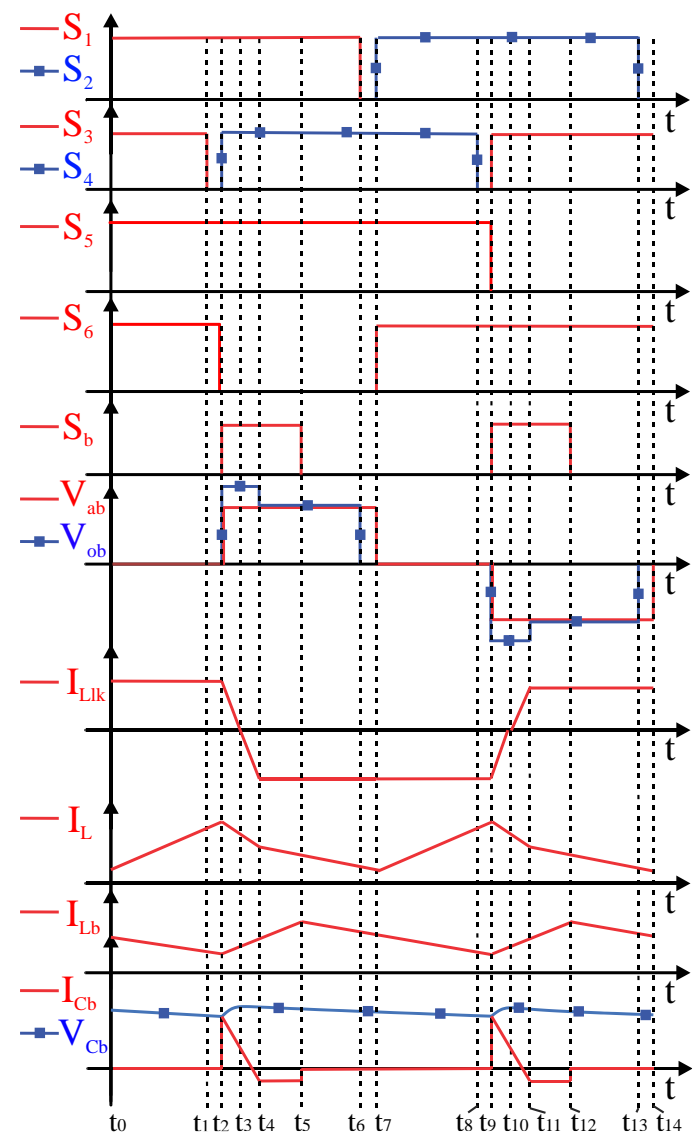

Fig. 6. Main waveforms of converter operating with negative power flow direction with time intervals $t_{0}$ to $t_{7}$ described.

\section{Characteristics}

The converter's duty cycle (D) is defined as the period when the inductor (L) discharges. Therefore, the main characteristics that can be derived from the converter's operation are time intervals, which are determined by

$$
\Delta t_{1}=(1-D) \frac{T_{S}}{2}
$$

$$
\begin{gathered}
\Delta t_{2}=\Delta t_{7}=\Delta t_{d} \\
\Delta t_{3}=\Delta t_{4}=\left(D-D_{e f}\right) \frac{T_{S}}{2}-\Delta t_{d} \\
\Delta t_{5}=\frac{L_{b} I_{L b}}{2 V_{C b}} \\
\Delta t_{6}=D_{e f} \frac{T_{S}}{2}-\Delta t_{5}
\end{gathered}
$$

Which $\mathrm{D}_{\mathrm{ef}}$ is the effective converter's duty cycle, $\mathrm{T}_{\mathrm{S}}$ is the total switching time, $\Delta \mathrm{t}_{\mathrm{d}}$ is the dead-time interval, $\mathrm{L}_{\mathrm{b}}$ is the buck inductance, $\mathrm{I}_{\mathrm{Lb}}$ is the buck inductance current and $\mathrm{V}_{\mathrm{Cb}}$ is the clamping voltage.

\section{MODELING AND CONTROL}

Some applications require a closed-loop control system, in order to the measured variable follow a reference. Thus, the converter transfer function that relates the variation of the inductor current $\left(\mathrm{I}_{\mathrm{L}}\right)$ with the complement duty cycle $(\mathrm{d})$ is determined to project the controller. The transfer function in the frequency domain can be found through small-signal AC model, as presented in [13].

Therefore, the block diagram presented in Fig. 7 describes the inductor current closed-loop control.

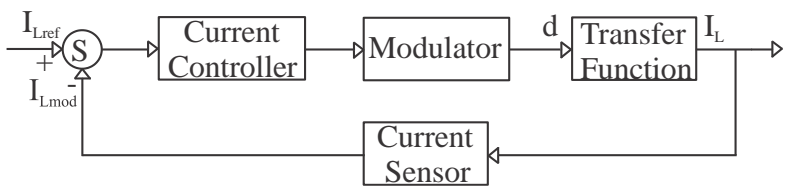

Fig. 7. Block diagram of the closed-loop current control.

To find the inductor current transfer function in relation to the complement duty cycle, the simplified equivalent circuit of the secondary side of the transformer will be analyzed. In summary, it presents two topological states shown in Fig. 8.

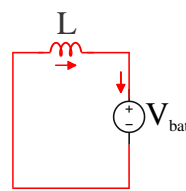

(a)

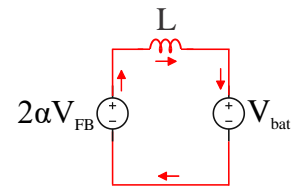

(b)
Fig. 8. Simplified equivalent circuit: (a) First topological state and (b) Second topological state.

(a) Time interval $\Delta \mathbf{t}_{1}^{*}$ : The first state represents the periods which the voltage across the transformer $\left(\mathrm{V}_{\mathrm{ab}}\right)$ is null because both switches $S_{5}$ and $S_{6}$ are gated on, as represented on Fig. 8 (a).

(b) Time interval $\Delta \mathbf{t}_{2}^{*}$ : At the second topological state, the voltage in the secondary side of the transformer is not null because one of the switches is turned off, as presented on Fig. 8 (b).

Then, the voltage across the inductor for time intervals $\Delta \mathrm{t}_{1}^{*}$ and $\Delta \mathrm{t}_{2}^{*}$ are given by

$$
V_{L}=-V_{b a t}
$$




$$
V_{L}=2 \alpha V_{F B}-V_{b a t}
$$

Using both inductance voltage equations, it is possible to calculate the transformer's voltage as

$$
V_{a b}=2 \alpha V_{F B}\left(1-\frac{2 \Delta t_{1}^{*}}{T_{S}}\right)
$$

Time interval $\Delta t_{1}^{*}$ can be divided into time that current stored in the leakage inductance is transferred to the voltage clamping circuit $\left(\Delta t_{L l k}\right)$ and the remaining period which the voltage across the transformer is null $\left(\Delta t_{a}\right)$.

$$
\Delta t_{1}^{*}=\Delta t_{a}+\Delta t_{L l k}
$$

Then, by replacing (9) into (8), the voltage $\mathrm{V}_{\mathrm{ab}}$ is found to be the sum of the voltage without influence of the leakage inductance $\left(\mathrm{V}_{\mathrm{ox}}\right)$ with its voltage drop.

$$
\begin{gathered}
V_{a b}=2 \alpha V_{F B}\left(1-\frac{2 \Delta t_{a}}{T_{S}}\right)-2 \alpha V_{F B}\left(\frac{2 \Delta t_{L l k}}{T_{S}}\right) \\
V_{o x}=2 \alpha V_{F B}\left(1-\frac{2 \Delta t_{a}}{T_{S}}\right)
\end{gathered}
$$

Therefore, an equivalent circuit that represents the voltage drop in the secondary side due to the leakage inductance can be found, as shown on Fig. 9.

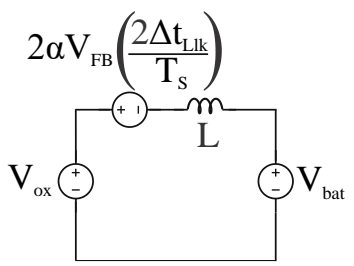

Fig. 9. Equivalent circuit with the leakage inductance voltage drop.

It is possible to replace the voltage drop of Fig. 9 with a resistance.

$$
2 \alpha V_{F B}\left(\frac{2 \Delta t_{L l k}}{T_{S}}\right)=R_{L l k} I_{L}
$$

To find the resistance $R_{L l k}$, it is required the time interval $\Delta t_{\text {Llk }}$, which is possible with the voltage across the leakage inductance $\left(\mathrm{L}_{\mathrm{lk}}\right)$.

$$
\Delta t_{L l k}=\frac{\alpha L_{l k} I_{L}}{V_{F B}}
$$

Finally, replacing (13) in (12) leads to

$$
R_{L l k}=4 \alpha^{2} L_{l k} f
$$

In addition, the complement duty cycle can be written as

$$
d=1-D=1-\frac{2 \Delta t_{a}}{T_{S}}
$$

Therefore, replacing (14) and (15) in (11) gives

$$
V_{a b}=2 \alpha V_{F B} d-4 \alpha^{2} L_{l k} I_{L} f
$$

Additionally, it is possible to substitute (16) in (11) to find a new equivalent circuit, as shown in Fig. 10.

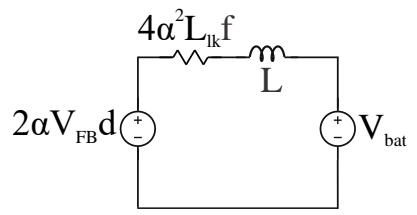

Fig. 10. Equivalent circuit with the resistance of the leakage inductance.

Then, by applying the Kirchhoff Voltage Law in the new equivalent circuit the following equation is found.

$$
2 \alpha V_{F B} d=V_{b a t}+4 \alpha^{2} L_{l k} I_{L} f+L \frac{d I_{L}}{d t}
$$

It is desirable to obtain the transfer function of the current $\left(\mathrm{I}_{\mathrm{L}}\right)$ in relation to the complement duty cycle (d). So, a perturbation is applied in those variables as follows

$$
\begin{gathered}
d=d+\overline{\Delta d} \\
I_{L}=I_{L}+\overline{\Delta I_{L}}
\end{gathered}
$$

Now, replacing (18) and (19) in (17) leads to

$$
2 \alpha V_{F B}(d+\overline{\Delta d})=V_{b a t}+2 L_{l k} f\left(I_{L}+\overline{\Delta I_{L}}\right)+L \frac{d\left(I_{L}+\overline{\Delta I_{L}}\right)}{d t}
$$

Therefore, by applying the Laplace Transform and doing some algebraic manipulations, the transfer is found.

$$
\frac{I_{L}(s)}{d(s)}=\frac{2 \alpha V_{F B}}{s L+4 \alpha^{2} L_{l k} f}
$$

Finally, a bode diagram is plotted with the model and simulated curves, as shown in Fig. 11. The value of each variable will be presented in section IV.
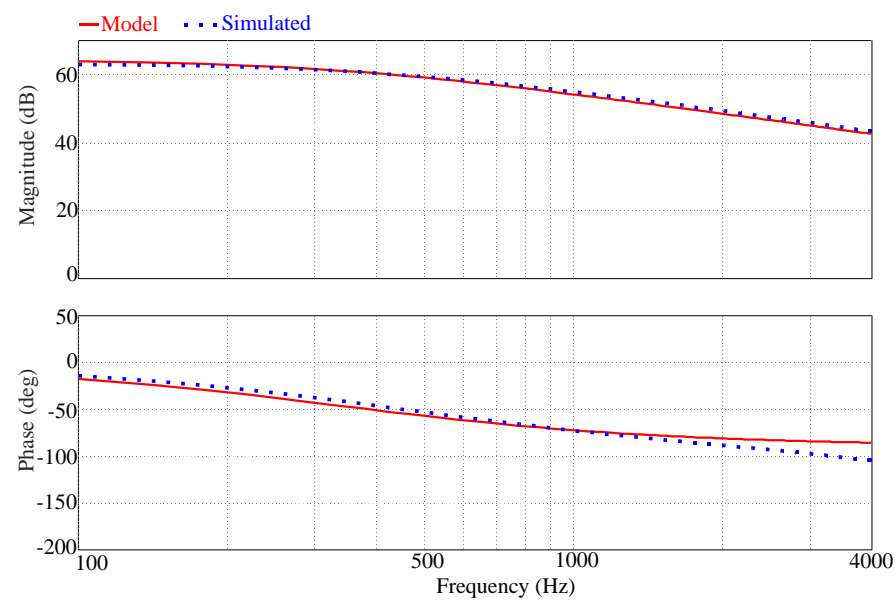

Fig. 11. Bode diagram of the model and simulated inductor current transfer function. 


\section{EXPERIMENTAL RESULTAS AND ANALYSIS}

In order to validate the theoretical analysis, an experimental prototype was developed, as shown in Fig. 12, following the specifications shown in Table I.

\section{A. Design}

Basically, the transformer's leakage inductance causes a lost in the duty cycle $(\Delta \mathrm{D})$ that is stipulated. Then, for a duty cycle (D) equals to 0.7 , the effective duty cycle $\left(D_{\text {ef }}\right)$ is calculated as

$$
D_{e f}=D-\Delta D=0.65
$$

TABLE I. SPECIFICATIONS OF THE PROPOSED CONVERTER

\begin{tabular}{lcc}
\hline \hline \multicolumn{1}{c}{ Specification } & Symbol & Value \\
\hline Rated Power & $\mathrm{P}_{\text {out }}$ & $2000 \mathrm{~W}$ \\
Primary Side Voltage & $\mathrm{V}_{\mathrm{FB}}$ & $400 \mathrm{~V}$ \\
Secondary Side Voltage & $\mathrm{V}_{\mathrm{bat}}$ & $48 \mathrm{~V}$ \\
Clamping Voltage & $\mathrm{V}_{\mathrm{Cb}}$ & $220 \mathrm{~V}$ \\
Switching Frequency & $\mathrm{f}$ & $40 \mathrm{kHz}$ \\
Clamping Circuit Frequency & $\mathrm{f}_{\mathrm{b}}$ & $80 \mathrm{kHz}$ \\
Minimum Power to Achieve ZVS & $\mathrm{P}_{\min }$ & $800 \mathrm{~W}$ \\
Duty Cycle Loss & $\Delta \mathrm{D}$ & 0.05 \\
Series Capacitor Voltage Drop & $\Delta \mathrm{V}_{\mathrm{Cr}}$ & $2.5 \%$ \\
Clamping Capacitor Ripple Voltage & $\Delta \mathrm{V}_{\mathrm{Cb}}$ & $1 \%$ \\
Inductor Ripple Current & $\Delta \mathrm{I}_{\mathrm{L}}$ & $10 \%$ \\
Clamping Inductor Ripple Current & $\Delta \mathrm{I}_{\mathrm{Lb}}$ & $10 \%$
\end{tabular}

The next equations are deducted in [10]. The transformer turns ratio can be calculated as

$$
\alpha=\frac{V_{b a t}}{V_{F B} D_{e f}}=0.185
$$

The current in the leakage inductance is given by

$$
I_{L l k}=\frac{\alpha P_{o u t}}{V_{b a t}}=7.692 \mathrm{~A}
$$

Furthermore, the leakage inductance is calculated as

$$
L_{l k}=\frac{V_{F B} \Delta D}{4 I_{L l k} f}=16.25 \mu H
$$

In addition, a capacitor in series with the leakage inductance is necessary to filter the DC level resulted from the commutation inequality of all the switches. This capacitor does not change the topological states and is determined by

$$
C_{r}=\frac{I_{L l k}}{2 \alpha f \Delta V_{C r} V_{F B}}=9.65 \mu F
$$

To achieve soft commutation, capacitors have to be placed in parallel with the MOSFETs in the primary side and a deadtime applied. The minimum capacitance is represented by

$$
C_{\min }=\left(\frac{P_{\min }}{V_{F B}^{2} D_{e f}}\right)^{2} \cdot \frac{L_{l k}}{2}=0.48 n F
$$

However, the commutation capacitance must consider the MOSFET intrinsic capacitance according to the component's datasheet. Therefore, with the sum of both capacitances, the commutation capacitance $\left(\mathrm{C}_{\mathrm{c}}\right)$ is used to calculate the deadtime.

$$
\Delta t_{d}=\left[\frac{\pi}{2}-\cos ^{-1}\left(\frac{V_{F B}^{2} D_{e f}}{P_{\min }} \cdot \sqrt{\frac{2 C_{c}}{L_{l k}}}\right)\right] \cdot\left(\sqrt{2 L_{l k} C_{c}}\right)=221 n s
$$
by

The current in the inductor at the secondary side is given

$$
I_{L}=\frac{P_{o u t}}{V_{b a t}}=41.667 \mathrm{~A}
$$

The inductance value can be calculated using the current ripple criteria

$$
L=\frac{V_{b a t}(1-D)}{2 f I_{L} \Delta I_{L}}=43.2 \mu \mathrm{H}
$$

The buck converter that will be used as a clamping circuit to limit the voltage across MOSFETs $\mathrm{S}_{5}$ and $\mathrm{S}_{6}$ can be sized according to the power that should be recovered. The buck's duty cycle presented in (31) varies according to the desirable clamping voltage, which the limit must be the MOSFETs breakdown voltage.

$$
d_{b}=\frac{V_{b a t}}{V_{C b}}=0.218
$$

Additionally, the time that the clamping diodes are forward biased $\left(\Delta \mathrm{t}_{\mathrm{g}}\right)$ can be calculated as

$$
\Delta t_{g}=\frac{I_{L l k} L_{l k}}{2 V_{F B}}=156 n s
$$

With the time necessary to the current reaches its maximum value, it is possible to calculate the maximum current through the clamping diode $\left(\mathrm{I}_{\mathrm{Dg}}\right)$ as

$$
I_{D g}=\frac{V_{C b} \Delta t_{g}}{2 L_{l k} \alpha^{2}}=31 \mathrm{~A}
$$

The current that charges the capacitor is provided by two clamping diodes and has a triangular waveform. Therefore, the power that the clamping circuit process is obtained as

$$
P_{\text {buck }}=2 f_{b} \int_{0}^{\Delta t_{g}} I_{D g} V_{C b} d t=170 \mathrm{~W}
$$

The Buck converter was designed to transfer up to $200 \mathrm{~W}$. Thus, the average current on its inductor can be calculated as

$$
I_{L b}=\frac{P_{b u c k}}{V_{b a t}}=4.167 \mathrm{~A}
$$


The buck inductor can be calculated using the ripple current.

$$
L_{b}=\frac{V_{b a t}\left(V_{C b}-V_{b a t}\right)}{f_{b} V_{C b} I_{L b} \Delta I_{L b}}=0.45 \mathrm{mH}
$$

In order to size buck's capacitor, it is necessary to calculate its RMS current $\left(\mathrm{I}_{\text {Cbrms }}\right)$, which is represented as

$$
I_{\text {Cbrms }}=2 \sqrt{f \int_{0}^{\Delta t_{3}+\Delta t_{4}}\left(\frac{I_{D g}}{2}\right)^{2} d t}=5.517 \mathrm{~A}
$$

Therefore, capacitor $\mathrm{C}_{\mathrm{b}}$ can be sized with the voltage ripple criteria as presented in (38). The RMS current must be smaller than the maximum presented in the component's datasheet.

$$
C_{b}=\frac{I_{C b r m s} d_{b}}{f V_{C b} \Delta V_{C b}}=13.667 \mu F
$$

The final prototype is shown in Fig. 12. All the necessary circuits and components are presented in [10]. In addition, the inductors and transformer were built by the author.

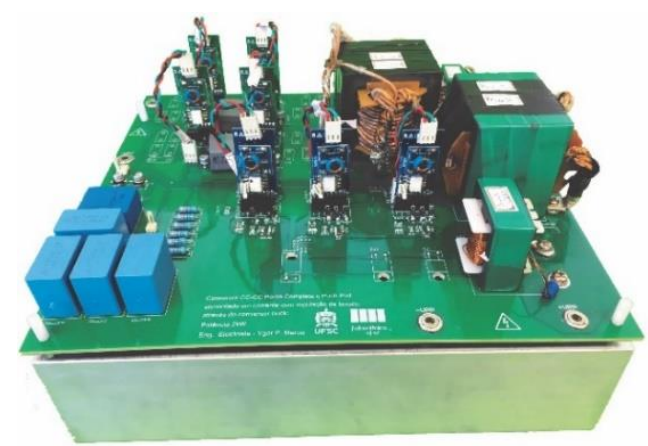

Fig. 12. Power stage of the experimental prototype of the proposed bidirectional isolated dc-dc converter.

\section{B. Experimental Results}

The experimental results were obtained by debugging the prototype for each power flow direction. Therefore, Fig. 13 represents the voltage on both sides.

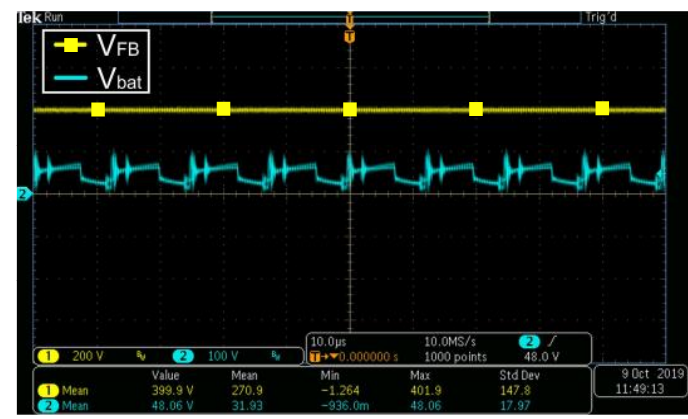

Fig. 13. Primary side $\left(\mathrm{V}_{\mathrm{FB}}\right)$ and secondary side $\left(\mathrm{V}_{\text {bat }}\right)$ voltages.

In addition, Fig. 14 shows the Zero Voltage Switching for the positive power flow direction, since $\mathrm{S}_{4}$ has no voltage across its terminals when the gate signal is generated.

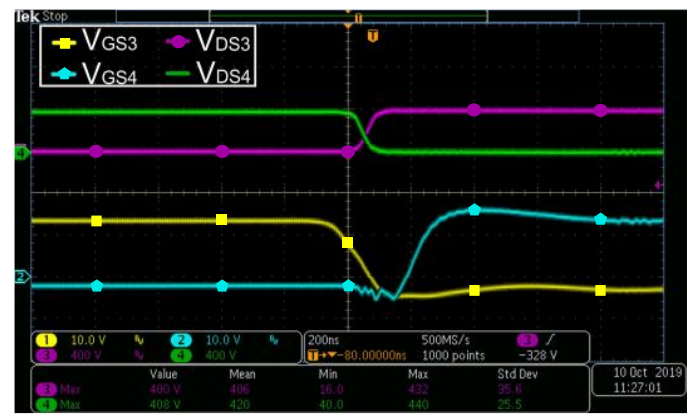

Fig. 14. Gate signals and breakdown voltage across switches $S_{3}$ and $S_{4}$ to prove soft switching in the positive power flow.

The clamping voltage shown in Fig. 15 can be set by changing the buck's duty cycle. Furthermore, $\mathrm{V}_{\mathrm{DS} 5}$ and $\mathrm{V}_{\mathrm{DS} 6}$ are the voltages across the switches $S_{5}$ and $S_{6}$, respectively.

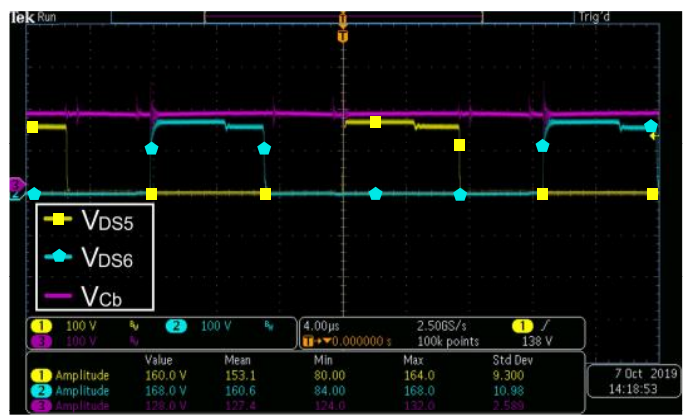

Fig 15. Clamped voltage across switches $S_{5}$ and $S_{6}\left(V_{D S 5}\right.$ and $\left.V_{D S 6}\right)$ with its clamping capacitor voltage $\left(\mathrm{V}_{\mathrm{Cb}}\right)$.

The current and voltage across transformer's primary side for both power flows are presented on Fig. 16 and Fig. 17, respectively. Note that differences between experimental and theoretical currents are due to gate signal delays between the switches, in practical experience, that inserted unpredicted topological states in the converter operation.

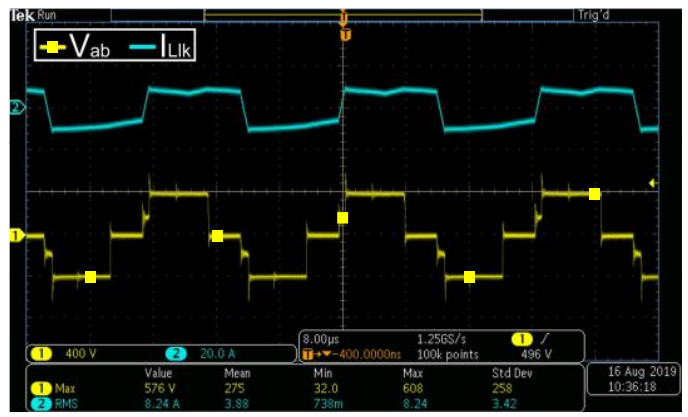

Fig. 16. Voltage across the transformer $\left(\mathrm{V}_{\mathrm{ab}}\right)$ and leakage inductor current $\left(\mathrm{I}_{\mathrm{Llk}}\right)$ for the positive power flow direction.

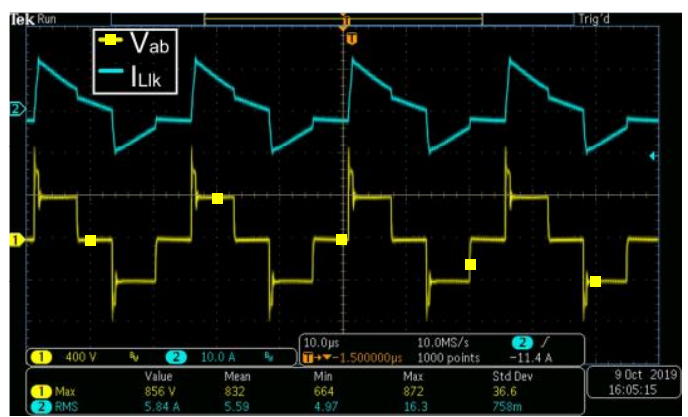

Fig. 17. Voltage across the transformer $\left(\mathrm{V}_{\mathrm{ab}}\right)$ and leakage inductor current $\left(\mathrm{I}_{\mathrm{Llk}}\right)$ for the negative power flow direction. 
The main current waveforms for the positive and negative power flows are presented in Fig. 18 and Fig.19, respectively.

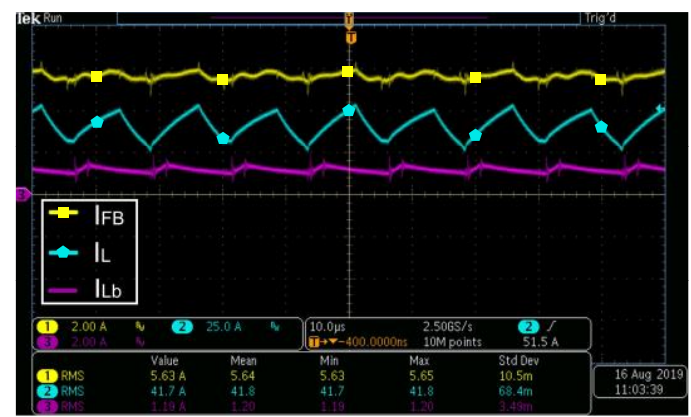

Fig. 18. Primary side $\left(\mathrm{I}_{\mathrm{FB}}\right)$, secondary side $\left(\mathrm{I}_{\mathrm{L}}\right)$ and clamping inductor $\left(\mathrm{I}_{\mathrm{Lb}}\right)$ currents for the positive power flow direction.

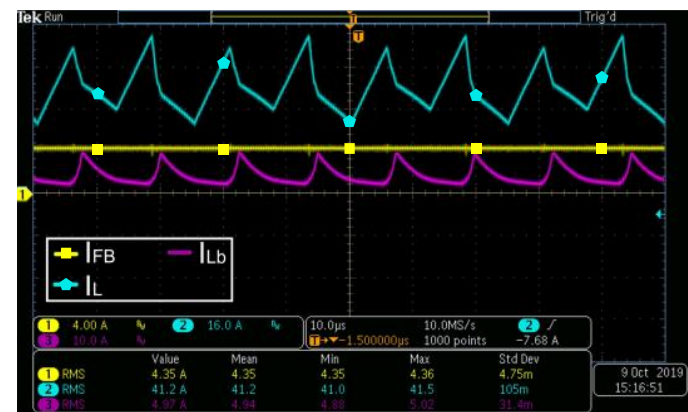

Fig. 19. I Primary side $\left(\mathrm{I}_{\mathrm{FB}}\right)$, secondary side $\left(\mathrm{I}_{\mathrm{L}}\right)$ and clamping inductor $\left(\mathrm{I}_{\mathrm{Lb}}\right)$ currents for the negative power flow direction.

Finally, the converter's efficiency was acquired for both power flows. In fact, for the positive power flow, two different set ups that considered hard and soft commutation were applied. Finally, Fig. 20 describes the converter's efficiencies as a function of the processed power.

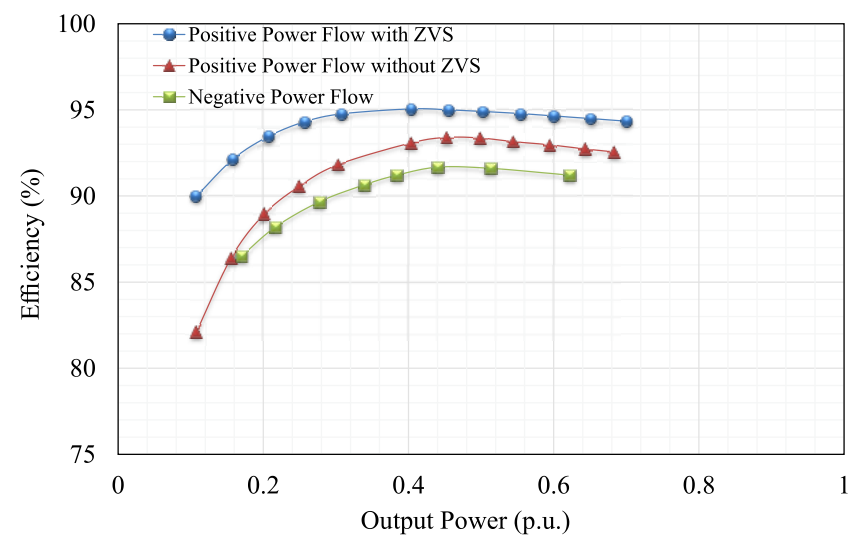

Fig. 20. Converter's efficiency for positive and negative power flows.

The maximum efficiency of $95.1 \%$ was acquired for the positive and $91.8 \%$ for the negative power flow. The experiments without soft commutation decrease the converter's performance by $2 \%$, which explain one reason that contributes to reduce the efficiency for the negative power flow.

\section{CONCLUSION}

This paper presents an alternative for bidirectional isolated DC-DC converter with high static gain based on the integration of the full-bridge ZVS-PWM and current-fed push-pull converters. The topology requires a clamping circuit to reduce the voltage across the power semiconductors of the secondary side and regenerate energy stored in the transformer leakage inductance. Therefore, by using a low power buck converter as an active voltage clamping, the bidirectional converter can be designed to operate with high efficiency and low breakdown voltage. The higher efficiencies acquired were $95.1 \%$ and $91.8 \%$ for the positive and negative power flow, for a non-optimized experimental prototype, which is an advantage among similar converters. Moreover, the experimental results obtained with a 2000 Watts prototype evidenced the converter's performance with low ripple current at the low voltage side, authenticating this topology for isolated bidirectional DC-DC applications.

\section{ACKNOWLEDGMENT}

The authors would like to thank the Strategic Research Group on Solar Energy at UFSC and the Brazilian Institute of Power Electronics and Renewable Energies for providing the necessary components and equipment on the elaboration of the prototype. In addition, acknowledgement is made for the staff support from both research groups.

\section{REFERENCES}

[1] M. Upasani and S. Patil, "Grid connected solar photovoltaic system with battery storage for energy management", in 2018 2nd International Conference on Inventive Systems and Control (ICISC), pp. 438-443, Jan. 2018.

[2] H. Daneshpajooh, A. Bakhshai, and P. Jain, "Modified dual active bridge bidirectional DC-DC converter with optimal efficiency," in Proc. IEEE 27th Annu. Appl. Power Electron. Conf. Expo., 2012, pp. 1348- 1354

[3] L. Zhu, "A novel soft-commutating isolated boost full-bridge ZVSPWM DC-DC converter for bidirectional high power applications," IEEE Trans. Power Electron., vol. 21, no. 2, pp. 422-429, Mar. 2006.

[4] F. Z. Peng, H. Li, G. J. Su, and J. S. Lawler, "A new ZVS bidirectional dc-dc converter for fuel cell and battery application," IEEE Trans. Power Electron., vol. 19, no. 1, pp. 54-65, Jan. 2004.

[5] M. Jain, M. Daniele, and P. K. Jain, "A bidirectional dc-dc converter topology for low power application," IEEE Trans. Power Electron., vol. 15 , no. 4, pp. 595-606, Jul. 2000.

[6] Gu, L., \& Li, P., "Hybrid PWM Control of Bidirectional DC/DC Resonant Converter for Low-Current-Ripple and Wide-Voltage-Gain Application," IEEE Applied Power Electronics Conference and Exposition (APEC), pp. 2158-2162, Mar. 2020.

[7] Zeng, Yangbin, et al. "A Parallel-Resonant Isolated Bidirectional DCDC Converter with Low Current Ripple for Battery Storage Systems." IEEE Energy Conversion Congress and Exposition (ECCE), 2019.

[8] K. Dadialla and R. S. Hardas, "Development of prototype model of DC-DC bi-directional converter." IEEE International Conference on Power, Control, Signals and Instrumentation Engineering (ICPCSI), pp. 1620-1623, June 2017

[9] G. Chen, Y. Deng, H. Peng, X. He and Y. Wang, "An optimized modulation method tor full-bridge/push-pull bi-directional DC-DC converter with wide-range ZVS and reduced spike voltage," IECON 2014 - 40th Annual Conference of the IEEE Industrial Electronics Society, Dallas, TX, 2014, pp. 1247-1253.

[10] Y. P. Marca, "Isolated Bidirectional DC-DC Converter Based on the Integration of the Full-Bridge ZVS-PWM and Current-Fed Push-Pull Converters for DC Microgrid", Federal University of Santa Catarina, Master Thesis, Florianopolis, 2019.

[11] I. Barbi and F. Pottker, Soft Commutation Isolated DC-DC Converters, Springer International Publishing, 1 ed., 2019.

[12] F. J. Nome and I. Barbi, “A ZVS clamping mode-current-fed push-pull DC-DC converter", IEEE International Symposium on Industrial Electronics. Proceedings, Vol. 2, pp. 617-621, 1998.

[13] R. W. Erickson and D. Maksimovic, Fundamentals of Power Electronics, Springer Science Business Media, 2nd ed., 2001. 


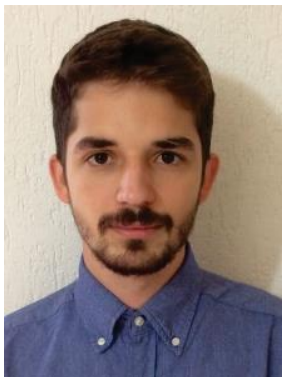

YGOR PEREIRA MARCA was born in JiParaná, Brazil. He received the B.Sc. degree in electrical engineering from the Federal Technological University of Parana (UTFPR) Curitiba, Brazil, in 2017 and the M.Sc. degree in electrical engineering from the Federal University of Santa Catarina (UFSC), Florianópolis, Brazil, in 2019.

$\mathrm{He}$ is currently working toward the Ph.D. degree at the Department of Electrical Engineering in the Group Electromechanics and Power Electronics at Eindhoven University of Technology (TU/e). His research interests include DC microgrids, electric vehicle chargers, high-power converters, isolated bidirectional DC-DC converters, soft switching and applications of renewable energy sources to decrease the environmental impact of energy production.

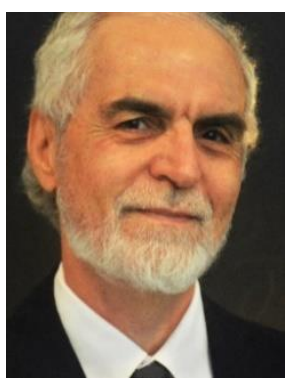

IVO BARBI (Life Fellow, IEEE) was born in Gaspar, Brazil. He received the B.S. and M.S. degrees in electrical engineering from the Federal University of Santa Catarina (UFSC) Florianópolis, Brazil, in 1973 and 1976, respectively, and the Dr.Ing. degree in electrical engineering from the Institut National Polytechnique de Toulouse (INPT), Toulouse, France, in 1979. He founded the Brazilian Power Electronics Society (SOBRAEP), the Brazilian Power Electronics Conference (COBEP), in 1990, and the Brazilian Power Electronics and Renewable Energy Institute (IBEPE), in 2016. He is currently a Researcher with the Solar Energy Research Center and a Professor Emeritus in electrical engineering with UFSC. Prof. Barbi received the 2020 IEEE William E. Newell Power Electronics Award. He was an Associate Editor for the IEEE Transactions on Industrial Electronics and the IEEE Transactions on Power Electronics, for several years. 